\title{
Perception and Passivity Can the Passive Pre-Givenness Be Phenomenalized?
}

\author{
Pedro M. S. Alves \\ Universidade de Lisboa \\ psalves2@gmail.com
}

\begin{abstract}
In what follows, I intend to address an issue which is at the boundaries of the phenomenological method of reflective explication, and that, in this sense, points to some limitations of the phenomenological approach to consciousness and mind. I am referring to an aporetic situation that is at the heart of the phenomenological analysis of passivity. On the one hand, phenomenology shows, at least indirectly, a passive life that is beyond the first steps of the activity of the ego in the receptive, affective life. This is something that is beyond the rising of an ego, and from which a phenomenology of the ego-form of subjective life could be addressed. On the other hand, the analytic and conceptual tools of the phenomenological method have no grips on this basic realm of subjective life. As a result, Husserl's analysis of passivity starts with the evidence of a pre-affective, pre-egoic realm, from which a phenomenology of the ego could be developed. However, Husserl's analyses end up with the denegation of this dimension, as if it was invisible for the phenomenological method. As a consequence, the starting point of the analysis is not passivity proper, but rather the primitive forms of receptivity, which is already a first layer of the activity of the ego. Instead of an analysis of the ego-polarization (the "birth" of the ego), the egoic layer of conscious life is simply presupposed. A phenomenology of the ego-form is, thus, at the same time promised and denied. This aporetic situation is visible in the alteration of the concept of a passive pre-givenness in Husserl's Analysis Concerning Passive Synthesis.
\end{abstract}

Keywords: Genetic Phenomenology, Passivity, Pre-affective Constitution, Activity, Husserl 
Nur eine radikale Theorie [...] kann das Rätsel der Assoziation und damit alle Rätsel des „Unbewussten“ und wechselnden „Bewusstwerdens“ lösen.

Husserl, Husserliana XI, 165

\section{Stating the question}

The issue I will address revolves around the relationship between both seizingupon (Erfassung) and still-holding in grasp (im-Griff-behalten), as lower strata of the perceptual activity of the ego, and their preconditions in the depths of passive life. At first glance, the issue appears quite simple: the passive preconditions are exhausted in their passage to the perceptual activity and nothing more remains there, so that every element of passivity is (or can be) taken and incorporated in a suitable active lived-process. However, in a closer look, qualms arise regarding the possible greater richness and extension of the realm of passive lived-processes, as well as of a passive form of the self that is not yet an ego, and regarding the way these passive processes connect to active intentional life, namely, to perceptual activity. Actually, one can wonder if all passive life is taken by the active strata, and if some passive processes do not take other routes of development instead of culminating in perceptual acts with an ego-polarization. In the framework of a phenomenology of perceptual acts, which are directed to individual objects in their appearing, these passive preconditions are characterized by Husserl as pre-givenness (Vorgegebenheit).

The general issue I will address concerns, then, a phenomenology of the pregiven in its own pre-givenness.

As used by Husserl, the concept of "pre-givenness" is double-sided. On the one hand, it refers to the individual objects that appear in perception as already being there in advance, before any active seizing-upon of consciousness. Individual beings are pregiven in the sense that they appear in perception as already there, regardless of any perceptual activity. Perception only encounters what exists in advance, although this "being in advance" is a meaning formation that springs from perceptual intentionality itself. Enlarging this object-centered approach, Experience and Judgment states that the world-belief is the universal pre-givenness of all experience, and this pre-givenness is characterized as 
signifying that the world is "what is always already there without any attention of a grasping regard, without any awakening of interest", prior to "any activity of cognition" (Husserl, 1939: 24). In such a conception, the world-presence is not the result of an achievement (Leistung); rather, it is something that has taken place since always. Without and before any active intervention of consciousness, it is something that simply befalls, lacking any backward-reference to a constitutive genesis. Every perceptual consciousness is caught in this pregivenness of objects appearing as already being there before perception, referring to an environment (Umgebung) of co-givenness, and lastly referringback to the world. These references (Verweisungen) from the individual objects to the environment, and from the environment to the world, are a structure of sense that permeates all objectual appearances as a pre-givenness. However, this objective pre-givenness of the world is posited by perceptual activity, and is only accessible through it.

In any case, this "presence" of the world is, by itself, not yet an appearance, and the world-belief is still formless and empty of a definite content. Only perceptual intentionality can put definite objects before us, giving a determinate content to the world-belief, and a definite shape to the objects that are pregiven with it. In perceptual activity, the correlate of the object-pre-givenness are the strata that underlie the rising of perception itself. In the framework of genetic phenomenology, they are referred to as the realm of passivity, and described as a set of sensory fields whose content precedes and prompts perceptual intentionality and the concrete appearance of individual beings, along with their horizons of co-givenness (Husserl, 1939: 75). While the pre-givenness of the world as such has no generative history (in consciousness and for consciousness, it has happened to it since always), the subjective correlate of this world-pre-givenness is accounted for as a genetic process in the realm of passivity, as if the primordial world-belief (Welt-Glaube als Urdoxa) could be captured in the framework of an "archeology" of perception.

This makes, on the other hand, the subjective-centered concept of a pregivenness. If the pre-givenness of the world is a meaning-formation only accessible by active, perceptual intentionality, the passive strata that underlay activity have a more complex relationship with perceptual intentionality. This complexity concerns a double-regime of visibility and invisibility of the passive realm according to whether one lives in the concrete performance (Vollzug) of 
an act or in the reflective objectivation of it. While the Vollzug entails a kind of invisibility of the proper structure of the lower strata, Reflexion is able to bring them to the surface. Indeed, as a set of already structured preconditions for perception, they show themselves, from the point of view of the ego's reflective awareness of its own receptivity in perception, as a passive field which has the sense of being always operative "in advance" (not simply "already there" in advance). By contrast, for the straightforward, object-oriented activity of the ego in seizing and explicating (i.e., both in receptivity and spontaneity), these preconditions appear as actual, available, and yet unstructured fields of sheer sensory data, in which the ego enters in the accomplishment of new meaninginstitutions (Ur-Stiftungen), as if structures were firstly shaped by the apperceptions that "animate" a formless, hyletic stuff. ${ }^{1}$

Thus, when seized from the vantage point of the ego's active accomplishments (Leistungen), passivity is covered by objectual experience, so that its proper laws and structures merge with the categorical structures of predicative synthesis and are not picked-up by themselves. For instance, it is the golden-yellow of the tea-cup that one perceives, already embedded in the predicative categorical structure (we see that the tea-cup is golden-yellow, even before the stratum of expression, Ausdruck), and not the sheer hyletic yellow affection that is detaching from a background and prompting the turningtowards (Zuwendung) of the ego. Hence, not only activity covers passivity, but it also shrinks dramatically its richness, because the only features that are discerned in it are precisely those that have given rise to the ego's activities in perception, predicative judgment, and so on. In a Kantian vein, we could say that passivity is subsumed under (and covered by) the schematization of the categorical forms. (I will return to this point).

\footnotetext{
${ }^{1}$ Albeit this is not the crossing-line between genetic and static phenomenology, because both are reflective approaches to the acts of consciousness, this notion of a formless content - perhaps imported from the Vollzug sense structure of the acts - is precisely the point of view of static phenomenology, relying on the contrast between intentional form (morphe) and sensory matter (hyle), connected by means of an animating apprehension (beseelenden Auffassung). See Ideen-I, section 85 (Husserl, Hua III/1, 191-196). Nevertheless, Ideen-II thematizes under the title of "esthesic-synthesis" a realm that will be further developed in the twenties as an analysis of passivity, in the broader framework of genetic phenomenology.
} 
Conversely, when reflecting upon the perceptual activity instead of living in the accomplishment of it, one can put into brackets ("abstract" or "exclude") the perceptual constitution as such in order to examine what underlies it as a precondition. Individual objects are originally given in perception. When the active constitution is put into brackets, then comes into the foreground what "precedes" it, since the individual objectivities constituted in perception are now "dissolved" in their lower strata. The richness of these strata can be exhibited then, as well as the kind of selection and rearrangement perceptual activity exerts upon them. These pre-objectual strata are, then, a pre-givenness as a kind of milieu for perception, i.e., they appear as a larger realm that was operating in advance for the ego "before" active, objectual constitution took place, selecting and rearranging some structured elements of it.

In this sense, the more general definition of passivity is a privative one: it occurs without any "ego-participation" (Ichbeteiligung); i.e., "passive" are all lived-processes that are not a product of a certain kind of activity referring to the sphere of the Ich-kann. By means of such wide definition of passivity, one can retrieve a much richer amount of lived-processes than when one narrowly defines passivity by reference to the sense-formations that underlie the acts of the form ego. My point is that the class of lived-processes that run their course without an ego is presumably much larger than the class of passive livedprocesses that enter on or give rise to acts of the specific ego-form.

Now, can we turn this subjective-centered pre-givenness into a thematic givenness? It would be a givenness of precisely what?

Let us take some stock of it. Firstly, as is widely known, the temporal order of these strata is misleading. When one states that passivity "precedes" activity, or that the passive pre-givenness was there "before" active constitution, this does not have a literal meaning at all. Rightly understood, the order of precedence points to an ideal genesis, and not to a factual history of subjectivity, and this ideal precedence is compatible with a constant intermingling and mutual dependency (not only as a fact, but, more strongly, as an essential law) between original passivity and activity. For genetic phenomenology, the origin, Ursprung, is not a beginning, Anfang. Secondly, with this bracketing, instead of a regression to a primitive form of subjective life, one is pondering the import of active constitution, and the linkage with some elements that appear in it as 
its necessary conditions. It is the content and structure of these layers conditioning perception and activity in general that are put together under the designation of "passive genesis". Thirdly, the "more fundamental" layers of constitution have not gone into an unrecoverable past. Quite the contrary, they are accessible right there in the active constitution by means of a methodic suppression of its proper achievements. Phenomenologically, origins and its derivatives are contemporary. Here, what is needed to exhibit them is a kind of zigzag movement, going back and forth from the bracketing of the perceptive world into the fields that come into the foreground, and then from those fields once again into the perceptual world, so that the connection between passivity and activity, and their own constitutive achievements, become apparent by means of this contrastive analysis. $^{2}$

This is what we are roughly told by a first reflection upon the whole issue. However, the picture that full-fledged phenomenology of passivity would convey is much more complex, so I believe. When pondered, this greater complexity would give us good insights into the lessons a phenomenology of perception could deliver in its linkage to and dependence on the passive livedprocesses.

One feature that turns this general picture into a more complex one concerns the phenomenological access to passivity and to the subject that undergoes passive life: as a process that unfolds "before" (that is, independently of) any import of active intentional life, passivity can be brought to givenness in phenomenological reflection only in an oblique way. Indeed, reflection presupposes the ego-form, an act with its intentional content, and then a turning towards itself of the ego, seizing its own activity and then the passive, pregiven milieu in which it is entrenched. However, if one endeavors to enter this latter realm in which there is not yet an ego as active, trying thus to seize directly what is there in sheer passivity, one faces a perplexing situation. This is so

\footnotetext{
${ }^{2}$ Referring to passivity in the opening section of Active Syntheses, Husserl alludes to this situation in the following words: „Es liegt in der Natur der Sachlagen, dass man von diesen Unterstufen nur sprechen kann, wenn man schon das fertig und aktiv Konstituierte vor Augen hat, und wenn man von der Aktivität abstrahiert, so ist sie zunächst unvermeidlich eine wesensmäßig noch unbestimmte, so dass erst die nachkommende Untersuchung der höheren Stufe auch für (die) untere Reinheit des Verständnisses ihrer Leistung geben kann.“ (Hua XXXI, 3)
} 
because, in the proper sense, there is no direct reflective givenness of what is pregiven since, here, there are no affection and no appearing objects in the pregnant sense, no intentional acts, and, even more, no intentional acts of the form cogito, so that all these processes take place in a "mute" subjective life, and, we may suppose, are in themselves not from the ego, albeit they remain there for the ego. Now, not being from the ego but remaining at the disposal (Vorhanden) of the ego raises the other side of the problem: what is precisely this "remaining there" and its subjective unity, then the "taking" (i.e., the moment of "affection", and the turning-toward), and, most importantly, seen phenomenologically, what is the ego and its proper achievements, inasmuch as it its determined by the taking of a realm already operating, and by bringing it to that particular form of meaning-structuration which we call its "activity"?

Thus, the endeavor to come-back phenomenologically to what always remains in the background as a precondition (better: a milieu) for the intentional acts of the ego raises some important issues. To put them straightforwardly, I ask the following two questions:

1. Can the passive pre-givenness underlying perception be properly "phenomenalized", i.e., converted into a pure phenomenon in the sense of phenomenology?

2. In sheer passivity, is an $e g o$ already there centralizing passive life, or must we adopt a multiplane, decentralized conception of passivity, putting a global Self that is not already a centralized ego as the subject which lives through it?

\section{Some necessary clarifications}

The two questions I just posed need some qualifications and complements.

Firstly, they presuppose a clear cutting-line between activity and passivity. Husserl writes that "passivity is in itself the first" (Hua XXXI, 3). However, the achievements of activity also sink back into passivity and are deposited in it as a sediment. They can be reawakened, affecting the ego from a milieu of "unconscious" life that is still there, while not in the form of explicit awareness. For instance, this is the case when the remembrance of a former perception that had completely disappeared from the field of actual intentional life suddenly comes to mind. Furthermore, the meaning-institutions shape the hyletic fields 
and give them unities of form that will return in further affections, which will have, then, a synthetic unity that springs not from pure passivity alone. As an example, three blotches of color are apprehended as a flag of a certain country, or several disparate noises as the single ring-tone of a cellphone. Then, when similar colors or noises detach from a new environment, even when it is pretty different from the original one, or when some parts of the colors or noises are now fused in the background, they carry with them the former unities of form, so that what strikes the ego is not a sheer passive datum with its idiosyncratic forms of unification, but already structured unities coming from previous apperceptions. Passivity can "learn" from activity how to shape its contents. In his lessons about passive synthesis, Husserl considers the issue en passant, while discussing the case of a man born blind and suddenly recovering his sight. Looking around without the mass of previous apperceptions already stored in his visual field (a kind of secondary passivity in original passivity), he could not figure out how to shape and interpret the ocular data, which would be displayed for him as a chaotic juxtaposition of hyletic contents, as if the syntheses proper to passivity were unable to settle an ordered domain without the guiding lines of former apperceptions. ${ }^{3}$

Indeed, there is a wide (and loose) concept of passivity that turns the distinction between passivity and activity into a relative one. If we only retain a general characterization of passivity as something that (i) is at disposal for the ego's activity, or (ii) is an act that underwent the modification of inactuality, or (iii) is a part of an act of the ego (like the "still-holding in grasp" in perception or in any other intentional act), then we can state that "the distinction between activity and passivity is not a rigid one" (Husserl, 1939: 119). Nevertheless, as Husserl himself has pointed out, there is also a passivity "before" activity, i.e., an originary passivity which, contrariwise to the so-called "secondary passivity", belongs not to the acts, as a passivity in activity or an activity turned into passivity, but which is an underlay (Unterlage) or something that lays beneath

\footnotetext{
${ }^{3}$ See Hua XI, 413. The problem which Husserl considers reminds the question that Molineaux addressed to Locke: if a man born blind and recovering vision suddenly could distinguish immediately, by means of his new ocular ideas, a globe from a cube, objects which he easily used to distinguish by means of his haptic ideas. The issue is discussed at length from a phenomenological perspective by Shaun Gallagher (see Gallagher, 2005, Chapter 7).
} 
every form of egoic, perceptual activity. This forms the narrow concept of a passive life. Its domain is not the temporal horizons of the stream of consciousness, but the apperceptions that take place in the living present. In entails: (i) not simply to be at the disposal of the ego for reactivation, but to be an actual pre-givenness that prompts the perceptual life of the ego, (ii) to be in a particular sense non-egoic or without the participation of the ego (ohne Ichbeteiligung), (iii) to develop under rules that are proper to it, not only going in advance regarding the synthetic forms that spring from the ego's new apperceptions, but also with the type-like apprehensions that permeate normal perceptual life (for these idiosyncratic rules of unification, Husserl uses the awkward concept of a "passive synthesis", which, at first sight, sounds like an oxymoron). So, as Micali rightly points out albeit referring himself to the anonymity of the I, "Husserl reveals a passivity that is not based on a regressive consideration [that is: it does not refer to the temporal horizons of the present], but appears right in the middle of the activity. This passivity has not to do with the dormant I, but with the highest mental activity of the ego" (Micali, 2008: 76).

Secondly, the questions I put forth entail that the concept of a transcendental subjectivity is wider than the concept of a transcendental ego. Indeed, as Holenstein once remarked, "the 'carrier' of the passive constitution is the protoflowing life, from which rises the ego of the active positings" (Holenstein, 1972: 213). This distinction has nothing to do with the question Husserl discussed in the fifth logical investigation, namely, if there is a pure ego as a phenomenological component of the transcendental constitutive life. As everybody knows, his position regarding this issue was drastically revised between the first and the second editions of the Logical Investigations. Nevertheless, while acknowledging with the Husserl of Ideen that, after the transcendental reduction, a pure ego remains as an identical pole of the acts of consciousness, a kind of "transcendence in immanence" (Hua III/1, 124), the problem is whether all life-processes exhibit this ego-polarization, namely when we move from active to passive life. In Ideen-I, Husserl has no direct account of passivity. He strictly argues from the point of view of the acts of the form cogito, and supposes that all life-processes which are not actually of this form can be turned into it. When addressing the question of the ego as an identity over and above the flow of consciousness, he writes, "We have spoken till now of life-processes of the notable form cogito" (Hua III/1, 179). Then, he 
recognizes that "certainly, the other life-processes [...] lack the ego-reference" (ibidem) However, he considers that those life-processes are still acts that experienced the modification of inactuality, so that they "have a share in the pure ego, and this last on them" (ibidem). Thus, he concludes, "they belong to it as 'its own', they are its consciousness' background, they belong to it as their 'realm of freedom"' (ibidem).

However, passive pre-constitution is not a "realm of freedom" for the ego. Regarding the hyletic contents that fill the living present and their associative blending, there is neither a reference to an origin in the ego, nor to an ego's intervention in framing their specific nature, or to a space of decision regarding what contents will further emerge in each sensory field. The "freedom", or the ego's participation, gradually starts with the turning-toward that responds to affections coming from this passive realm. However, the contents (accompanied or not by a Reiz and an Affektion) spring sponte sua, so to speak, in the flow of mental life. While acts are characterized by an auto-spontaneity, passive processes spring from a hetero-spontaneity, pointing to a nucleus of what is Ichfremd, i.e., alien to the ego. Even if these contents are wholly subjective, they are not ego-like life-processes, so that one must distinguish, as a matter of principle, between life-processes with an ego-polarization, and mental processes without an ego, i.e., life-processes where the ego is neither an origin, nor a constituent.

So, instead of following Husserl in the assumption of a "passive participation" of the ego as center of affections, as Einstrahlungspunkt, already present in the realm of original passivity, in my questions I am suggesting another way of dealing with the difference between the global flow of lifeprocesses and those that have the sense of being acts of an ego, of having the form-cogito. Namely,

(i) that the ego as a "convergence center" of affections is already at the crossroads between sheer passivity and plain activity - indeed, the constitution of something like an affective center for otherwise disparate sensory processes (interconnecting parallelly, in the best case) is the very starting point of activity;

(ii) that the subject of passivity is inseparable from the somatic (leiblicher) organism, which constitutes itself in the stratum of kinesthetic processes that run their course in connection to the flow of hyletic contents; 
(iii) that the ego that rises in activity and, more precisely, in perceptive life, as it comes over passive pre-givenness, is already deeply enrooted in the former constitution of somaticity (Leiblichkeit); thus, even if, contrary to sensations, egoic acts are not bodily localizable, the ego arises there not as an ego that "has" a body, but as an egoic higher form of organization (a kind of projection into a virtual, disembodied center) of a somatic, bodily subject; and finally

(iv) that (a thesis that goes fairly beyond Husserl) not all passive life-processes give rise to acts, let alone to acts of the form-cogito, and even when giving rise to acts, they do not need to be necessarily of the form-cogito, so that there is a multitude of life-processes in the flow of constitutive life that take other routes of development instead of culminating in experiences with an egopolarization. For the totality of life-processes forming a systematic unity and displaying a sense of selfhood, in which those that have the form ego are only a part, a possible name would be precisely the word that Husserl borrowed from Leibniz: monad. There, like in Leibniz's lesson, not all perceptions are apperceptively grasped, and there is plenty of room for those "small perceptions" (petites perceptions), and "perceptions without apperception" (perceptions inaperçues) that make-up the rich, concrete content of the mind. If this proves to be right, then we would be reaching the limit-point where a phenomenology of life-processes would not be only a phenomenology of consciousness (Bewusstsein), but would point to what Husserl called a "phenomenology of the unconscious".

This latter assumption, which is implied in my questions above, is not a denial or a downgrading of the relevance that the ego-polarization has for subjective life. Certainly, it entails that intentional life and its ego-centering is embedded into a wider and richer complexity of life-processes than those that come precisely into the ego's fore. It also entails that there are intentional acts which, while they exhibit a directedness toward objects, they do not have the phenomenal character of a thematic awareness that is proper to the acts of the form cogito. It finally entails a critique of the image of a self-sufficient subject which is, or can be, aware of all that happens in its mental life. Nevertheless, as I have declared, this is not tantamount to downgrading the role of the ego in mental life. Quite the contrary, the "birth" of the ego displays a sense of subjectivity and personal identity which is the most sophisticated mark of human mental life. In addition, it gives rise to a kind of atopic, virtual center of mental 
life that "detaches" from the body precisely as the "I" - the "eye of the soul", so to speak, now in contradistinction to the sheer organic body. Hence, the unity and difference between Leib and Ich. However, only if we regress to a more primitive dimension of life-processes that do not yet have the sense of an ego, while displaying a wider sense of a self, will we be in a productive position to account for the significance of the emergence of the form cogito and its egopolarization in subjective life, as well as the impact this stratum has in bringing about higher forms of mental organization. Thus, instead of downgrading the ego, I am searching for its proper accomplishments. Indeed, the ego is not a thing, and the very word is not a noun, but a pronoun. As such, the ego is not the mental life itself, but a function that operates in it. The issue is precisely what this function is.

\section{A way of looking through the keyhole...}

By itself, passivity has no narrator. It lacks an ego which would "live-in" and "through" it, which could then reflect upon its own life and report its deeds. For the ego, original passivity is rather a setting, a milieu, over and against which its activities are performed. The phenomenology of the ego is the description of the linkages that give several forms of unity to the passively pregiven, establishing new noetic structures (the "acts") along with a new central reference point for subjective life (the ego as Einstrahlung- and Ausstrahlungspunkt). Emerging over passivity, the acts of the ego do not develop against a background of external/transcendent things, but rather against a milieu of already subjective, although not egoic, life. This is our guiding thread.

However, one cannot help but wonder if it really makes phenomenological sense to talk about life-processes that are not by themselves conscious as "mine" in the first-person perspective. As Husserl himself put it, this kind of supposition would simply be a "substruction". (Hua XI, 163). This is the reason why his phenomenology of passivity properly starts with the concepts of ReizAffektion, Zuwendung-Weckung, and Aufmerksamkeit-Interesse. Even association is, sometimes, pushed to the side of affection, taking the affective awakening not as a form of associative synthesis, but as if it covered the whole 
associative phenomenon. However, the concepts that range from Reiz to Interesse are already the beginning of the Ichtendenz that becomes a Tun des Ich in a broad sense, also including the logical reason. So, in Husserl's approach, both the structures of the hyletic fields and the formation of unities of contents therein, which lie in the background, are only recovered afterwards, from the vantage point of the first steps of the ego's emergence in affective receptivity. As he emphasized, "we can only obtain decisive insights into the essence of association when we ... bring to a lawful understanding the function of affection" (Hua XI, 163); going a step further, he then tentatively universalizes the constitutive role of affection, saying that "it is ... quite probable that affection already plays its essential role in the constitution of all objectlike formations such that [without it] there would be no objects at all and no present articulated with objects" (Hua XI, 164). Passed on to affection, the passively pregiven hyletic contents are now experienced as something that is "mine", that is "my own" passive-receptive life: the yellow which I see, the ring-tone which I hear, and so on. Nevertheless, despite this thematic turn to affection, "before" (better: without) affection, the contents should already be wholly subjective states instead of nothing. They should form the first "subjective possession" not of, but for an ego, they should already have "a subjective being" as a "being for the subject" (not an "an sich") at the very thresholds of the latter egoic-centralization, as Husserl suggested it in the second volume of Ideas (Hua IV, 214-215).

The glimpses we can obtain about this "before" or "without" the ego's affective receptivity have an overall importance for a phenomenology of passivity. The first thing to stress is that this pre-affective stratum is not an illusion produced by means of a retrospective "substruction". Affection must have a "before" (or a "without"), a something that is brought to affective receptivity or, in a more straightforward rendering (which I will criticize later), a something that affects. This something is not a thing in a causal connection with the ego, as in Kant's doctrine of the Affektion of the Gemüt by a Ding an sich. Rather, it is a wholly subjective lived-process, already running its course unnoticed in a zero-degree of allure for the ego, so to speak.

As I said earlier, this pre-affective stratum is only accessible in an oblique way by a kind of phenomenological "inference". It will have the general form: 
Inference rule (IR): If $\mathrm{x}$ is given, then $\mathrm{y}$ was necessarily pregiven, considered that the givenness of $\mathrm{x}$ shows with evidence its relationship of dependence on $\mathrm{y}$, as its pre-givenness, even though the pregiven as such cannot be turned into something given.

As I stressed, this back-reference does not amount to establishing a causal link between allure-affection (Reiz-Affektion) and outer things. It is rather a sense formation in and of the given as such that points back to life-processes that were, by themselves, independent of being or not brought to affection. The dependence which is here pointed as a general connection can signify, specifically, a part-whole relationship (when the pregiven is contained as a part of a perceptual act and accessed only within it, for instance); a triggering relationship (as when some unnoticed visual contents trigger a sudden movement of the body, for instance, for escaping a menacing object, even before it is consciously seen), and so on (I will return in detail to this essential issue). Thus, the obliqueness of the phenomenological seizing is not tantamount to a losing of evidence. It is not an inference from the known into the unknown. Really, it is a back- or a downward reference, fully highlighted by itself, which goes either from what is given in the living present to what was pregiven in a former living present, or from what is given in the living present into what underlies this givenness in the very same living present. Even though passivity without affective allure points to a phenomenological "unconscious", there is a conscious evidence that it must be there if some acts are performed, given that those very acts point to these passive life-processes (even when they cannot be fully retrieved).

\section{Formation of unity and affection: the vicious circle}

I will substantiate my point above by means of two remarks.

Firstly, the raising of affection along with its propagation (Fortpflanzung, i.e., all the affective awakenings that are ruled by associations of the form: "this points to that") is not constitutive of the overall structures of prominence (Abgehobenheit), and contrast (Kontrast) of the sensory fields in the living present. Rather, the opposite is true: if affection was already a condition for the structuration of the living present, then the affectio would be creative of its own affectans, it will spring out of nothing, 
so to speak. ${ }^{4}$ Indeed, if affection supposes something detaching itself, and if this very contrastive detachment is already a function of affection, one faces an embarrassing vicious circle at the most primitive stratum of objective constitution.

Steinbock has pointed to this difficulty. ${ }^{5} \mathrm{He}$ recognizes that a kind of circularity is hovering over this issue. ${ }^{6}$ The solution he proposed, based on the Husserlian principle of the "relativism of affection" and its "gradualism", amounts to a universalization of the constitutive role of affection, so that, in a strong sense, there are no "neutral", non-affective objects (1995: 155). More recently, Bégout refused Steinbock's construal (which follows one side of Husserl's own account) stressing that the gradualism of affection necessarily presupposes a gradation that decreases till a zero-point, and thus to a realm of non-affective structuration of the living present, so that the problem remains in need of an answer, because "it leaves open the possibility of a non-affective constitution" (Bégout, 2000: 191). Thus, according to Bégout, the problem of a vicious circle still remains open, as the problem of the relationship between affective constitution and pre-affective structuration of the living present.

\footnotetext{
${ }^{4}$ For Husserlian, genetic phenomenology, there is not something like an auto-affection. Affecting itself would be a paradoxical starting point for conscious life. In a sense, the concept of an auto-affection is a reversal of the Fichtean speculative hypothesis of a Tathandlung. Whereas, for Fichte, life begins with an unconditioned act of positing itself for itself, here, life begins not with a hauto poien but with a hauto paschein. Nevertheless, the circular construal is the very same, and it is not phenomenologically (that is: positively) verifiable. By contrast, if one considers that what affects is already a sensible life-process, and not an external thing, there is a sense in which the talk about autoaffection has a good phenomenological sense. However, the sensory contents, when affecting, have the sense of delivering something which is Ich-fremd, alien to the ego.

5 In his own words: "When something becomes prominent for me, is it there in its prominence, awaiting, 'neutrally,' my affirmation or selection; or does it already exercise some influence on me, luring me to take it up? Or again, are there unities of sense that could come into being independently of affection if the 'relevant conditions' of becoming a unity are fulfilled (e.g. concrescence, contrast, etc.); or does a unity of sense, even the most elementary phase of the living present, co-originate with affection in order to be precisely this sense-unity? Put more simply, does affective force presuppose prominence or does prominence presuppose affective force?" (Steinbock, 1995: 153).

6 “ ... if sense constitution did presuppose affection, would not the very constitution of sense somehow presuppose, paradoxically, that sense was already constituted so that it could exert an affective force on me in order to be constituted?" (Steinbock, 1995: 154).
} 
I consider Bégout's criticism to be quite accurate. It is, so I believe, tantamount to pushing the genetic analysis to an unconscious (pre-affective) stratum, recovering the many gradualisms, layers, and directions of the processes by which it becomes a conscious life. In my opinion, what seems like a paradox making conscious life spring from unconsciousness - is rather the very opportunity to raise the radical questions about what is consciousness as a distinctive property of almost all (but not all) lived-processes. Indeed, the very heart of the problem is disguised by a badly posed/misguided question when one wonders how conscious life springs out of unconsciousness; on the contrary, it reveals itself when one rightly asks about what happens when some subjective structures of the living present that do not need to be affective in order to exist become affectively conscious, and then conscious as egoically "mine".

Further, - and this is my second, quite long remark - that the several sensory fields have an internal structure which is not dependent upon affection is a controversial point not only in the literature but even for Husserl himself. Indeed, he addresses the question in a rather aporetic section of his lectures on passive syntheses (Hua XI, 159-166, section 34). He tackles the problem in the form of a relationship between the formation of unity (Einheitsbildund) and affection. His conclusion is an unstable point of equilibrium between two opposite trends concerning the constitutive role of affection.

The question addressed in section 34 was raised in section 32. There, Husserl stated that "affection presupposes prominence above all else", and that prominence, in the living present, must be accounted for as "a fusion that takes place under contrast with respect to content", so that "contrast is to be characterized as the most original condition of affection" (Hua XI, 149, my emphasis). Affection has contrast as its condition, instead of being identical with it. A few lines earlier, Husserl has even taken the risk to define affection as "a function of contrast", while there is not a mechanic causal relation between the magnitude of contrast and the rising of affection. For this reason, Husserl then asks directly: "what gives a single prominent datum the priority of affection?" (ibid., 150). What he has in mind is that the living present is structured as a complex system of fusions and prominences that relate to each other, regarding their content (inhaltlich), under contrast. His question is about how affection connects selectively with one prominence instead of others, given that the latter also fulfill the "conditions for affection" and one must, thus, 
suppose a "relativism of the affective tendencies". He then deepens his enquiry by raising the question: "what kind of laws, and ultimately laws of essence, are here dominant?" (ibid.). However, he only gives a provisional, while interesting answer, based on the connection between affection and contrasts, feelings (Gefühle), and even drive (Trieb), proceeding then to another matter. ${ }^{7}$ Now, the propagation of affection is his new concern, leaving undecided the fundamental issue regarding the relationship between prominence and affection.

However, section 33 vacillates. An insidious doubt begins to make its way, as if the question left behind haunted the further course of the lectures. As a matter of fact, Husserl falls constantly in the former, unanswered question when he tackles his new problem of the laws regulating the propagation of affection. Apparently, he dispenses with the earlier problem, proceeding with the following words at the very outset of the section: "Suffice it to say that, in the relativism of affective tendencies, something [...] has necessarily become affective as such." Then, the new question is raised, which supposedly can be dealt with independently of the previous one: "[...] are there not laws concerning the propagation of this first affection?" (Hua XI, 151). However, in the course of this section dedicated to the phenomenon of the Fortplanzung of the affective awakening, the previous tension between formation of unity and affection becomes more and more acute. He wonders explicitly whether what was described under the concepts of concrescence and contrast is actually independent of affection, and denies that such an independence exists at least in the case of successive wholes, like a melody (Hua XI, 152). The case of successive unities suggests, then, that association is a function of the propagation of affection. If this situation is generalizable, then the affective awakening will engulf all associative constitution and the very formation of

\footnotetext{
${ }^{7}$ It is worth noting that Husserl suggests here, precisely where he is explicitly interested in essential laws, an experimental, qualitative research, opening the gates for a fruitful interplay between laboratorial experience under controlled conditions and the establishment of eidetic laws. His words are: „Das wären natürlich eigene Themen für Untersuchungen, wobei ein passendes Experimentieren, nicht ein induktiv-objektiv gerichtetes, wohl möglich wäre: Es hätte die Aufgabe, günstige Bedingungen der Herstellung reiner Fälle fraglicher Art herzustellen“ (Hua XI, 150-151). As far as I know, the qualitative lab-research conducted by Liliana Albertazzi at the Laboratory of Experimental Phenomenology, in Trento, goes in this direction.
} 
unity. Indeed, at the middle of section 33, a new, revised position is sketched, which amounts to (i) rendering every actual formation of unity dependent on affection; (ii) taking concrescence and contrast, as well as the temporal and local structure of the impressional fields, as mere conditions of possibility for affective, objectual constitution; (iii) pushing the phenomenon of association entirely to the side of affection. ${ }^{8}$ The culminating point of this new direction is a reframing of the concept of pre-givenness. This explicitly happens later on, in section 34, when Husserl writes that "Any kind of constituted sense is pregiven insofar as it exercises an affective allure [Reiz], it is given insofar as the I complies with the allure and has turned toward it attentively, laying hold of it" (Hua XI, 162, my emphasis). In a word: affection would be the most primitive level of sense formation; there would be nothing like a pre-affective stratum of constitution, and, therefore, the pregiven and the given would be the very same thing, depending whether, relative to it, there is only Reiz and Affektion, or also Zuwendung and Aufmerksamkeit.

However, this is only the new trend of analysis. The older is not suppressed, but coexists with it in the very same section. Husserl returns to it when, for describing the phenomenon of affection, he urges his audience to "assume that the prominent is already constituted, may it already be affective" (Hua XI, 154, my emphasis). Regarding the accidental or essential role of the accompaniment of every prominence by a concomitant affection, his answer is nuanced, while tending to the thesis of its non-essentiality. Indeed, that affection cannot accompany every prominence as an essential, constitutive feature of it is shown by the evidence that not all affections arise "trough the awakening of another affection", as in the case of a sudden explosion (Husserl's example). However,

8 „Drücken nicht am Ende die Wesensgesetzmäßigkeiten der immanenten Einheitsbildung, die wir beschrieben haben, die der Bildung für sich abgeschlossener einzelner Gegenstände, Ganzer, Gruppen, Konfigurationen bloße Bedingungen der Möglichkeit solcher Einheiten aus - während das wirkliche Zustandekommen dieser Einheiten selbst von Affektion und Assoziation abhängt? [...] Für uns konnten diese Einheiten nur da sein entweder als direkte gegebene im Rahmen der Aufmerksamkeit oder dadurch, dass wir rückgreifend in die Vergangenheitshorizonte einer Aufmerksamkeitssphäre nachträglich Einheiten erhaschten, die uns ohne und vor der Aufmerksamkeit gegeben waren, also uns doch zum mindesten affiziert hatten. Also überall spielt die Affektion und ersichtlicherweise auch die weckende Übertragung von Affektion, somit Assoziation ihre Rolle." (Hua XI, 153, my emphasis) 
this only proves that there are several chains of competing affections, instead of an ever growing one, and not the independence of prominence from affection. However, the other example of an unarticulated affection of an articulated whole (a string of lights) shows that there are at the bottom "pre-affective lawful regularities of the formation of unity" (Hua XI, 154). The articulated string detaches itself as a whole and affects, letting one infer that a pre-affective formation of unity (three lights put together as a unity of similarity under contrast) must exist running its course before the whole formed through it can affect as a single datum. Formation of unity (prominence under fusion and contrast) is, thus, different and more fundamental than affection and its propagation. There is a "zero-point" where affection begins, and a passive process behind it. This restores the former trend of Husserl's analysis.

It is at the crossroads of these two trends that section 34 explicitly raises the question of the relationship between formation of unity and affection. It is a very intricate section, et pour cause, could one say. The initial dilemma amounts to (i) presupposing the "object like" structuration of the living present and to consider that the rise and the propagation of affection are bounded to it, or (ii) as "suggested previously in our last lecture", stating tentatively "that affinity, continuity, contrast are relations that need not yet be viewed as an actual fusion-in-itself, as actually producing a unity in and through prominence" (Hua XI, 159). The second horn of the dilemma entails a further distinction between "unconditionally necessary fusions" that are independent of affection, like the temporal form and the local form of the field of living presence, as well as the "streaming" of the hyle, and those "fusions, formations of unity that are owing first to affection", where "special unities are constituted". In opposition to the first hypothesis, the point is whether the "object like" structure of the sensory fields in the living present is already a function of a constitutive role of affection, so that affection will constitute the unity of its very content. The danger of circularity emerges just here.

Nevertheless, giving expression to the new trend of analysis of the former section, Husserl takes the decision of examining if "such a theory is tenable" (Hua XI, 160). After a brief analysis based on the distinction between lower and higher orders of the formation of unities (prominences related to punctual fusions in the sensory fields and, then, synthetic unities at a distance, like similarities), he finds such theory "untenable", because "it is incomprehensible 
that fusion should first be generated through the unity of affection" (Hua XI, 161). Is, then, the first hypothesis the right one? Husserl doubts that, because, the other way around, the first horn of the dilemma also leads to a dead end. The reason is a straightforward one. Were the object-like structuration of the living present already constituted independently of affection, then it will be "incomprehensible" how "something should gain an affective force at all where nothing of the sort was available". In other words, it would be incomprehensible how "a pure affective nothing should become an affective something for the first time" (Hua XI, 163).

The aporia is quite clear: the relationship between formation of unity and affection remains incomprehensible in both cases. Firstly, because a null-point of affective force, a "neutral" object, as Steinbock says, is certainly something "in itself", as Husserl risks to affirm, but it is then hard to find out how, afterwards, it becomes something for the ego. Secondly, if every constitution of unity was already a function of affection, then we will have something like an affection that frames the very content that is affecting it, a circular proto-affection creative of its very content. To a certain extent, Husserl's way out is a reframing of the theory he judged "untenable" a few pages above. It states the co-originality between Einheitsbildung and Affektion. As he puts it: "for themselves, unities are constituted according to the principles of concrescence and contrast that we have demonstrated - as unities for themselves they are eo ipso also for the ego, affecting it". (Hua XI, 163, my emphasis). This is the principle of the gradualism of affective force. It tends asymptotically to a zero-point limit which is never attainable. Every objectual constitution in the hyletic fields is at the same time wrapped by an affective allure for the ego, be it quasi unnoticeable. The associative awakening, Husserl says now, shows that the content that is reached by the propagation of affection was already something weakly affecting the $e g o$, and not an "affective nothing". As a result, Husserl puts forth the methodological principle that we must "ascribe to every constituted, prominent datum that is for itself an affective allure [Reiz] acting on the ego" (Hua XI, 163). As I said early, this is tantamount to reframing the very concept of a pre-givenness. In this construal, pre-given would be the same as affecting, and the given will mark the point where turning-towards and attention begin. The traces of a pre-affective stratum of constitution are erased. 


\section{A provisional conclusion}

This is a very elusive point, indeed. On the one hand, only what affects is there, exists for the ego. The very concept of a pre-affective stratum would be, then, devoid of sense. Therefore, there is no für sich sein, only a für mich sein, to use Husserl's expressions; there is, then, no question about the way what supposedly is kath'auto becomes something pros hemas, as Bégout as pointed out (2000: 194-195). However, on the other hand, if there is an allure and an affection, then an articulated or unarticulated unity strikes the ego, and this unity does not depend on striking for being there. Quite the contrary: it must first be there in order to strike. Even though the prominence (or unity) that affects can be noticed as such only while affecting, and even though it is only through this noticing that the unity detaches itself as a prominence in a certain sensory field, nevertheless the affective awakening only catches this structure as being what it is, giving to it some relief. The sensory fields should have some internal, proper structure in order for something to become noticeable as a prominence by way of a contrast. For instance, two colored rectangles on a white background exert an allure and affect. I turn to them attentively and interpret them as the sensible appearance of two paintings hanging on the wall. Only while affecting do the sensible colors and the sensible forms display their status as prominences. This is right. However, in order to detach and affect the ego they must have been already configured in the ocular field as colors covering two coexistent rectangular forms. This is the other, non-obliterable side of the question. We must build an account that encompasses this pre-affective stratum. This is not tantamount to talking about a für sich sein of the hyletic data. Indeed, there is a closed interdependency between the formation of unities and the affective processes, so that the distinction is not really a separation. In this sense, one would be completely misguided if asking how a unity, that is wholly constituted, affects then the ego, instead of remaining locked in its "being in itself". Recognizing a good sense for talking about a pre-affective stratum does not commit us with such type of questioning. What it entails is a deeper concept of subjectivity that understands the pre-given as pre-affective and pro-affective, that is, as something that can be submitted to the unity of an affection, so that something like a "passive synthesis" (precisely Husserl's apparently awkward name) takes place here, joining together 
the passively constituted structure of the sense field and its unified relief in receptivity.

Consequently, what is in need is an account that puts the question of a phenomenological description of the raising of affection, instead of starting with it.

\section{Bibliography}

BÉGOUT, Bruce (2000). La généalogie de la logique. Husserl, L'antéprédicatif et le catégorial. Paris: J. Vrin.

BICEAGA, Victor (2010). The Concept of Passivity in Husserl's Phenomenology. Dordrecht: Springer.

Gallagher, Shaun (2005). How the Body Shapes the Mind. Oxford: Oxford University Press.

Holenstein, Elmar (1972). Phänomenologie der Assoziation. Zur Struktur und Funktion eines Grundprinzips der passiven Genesis bei E. Husserl. The Hague: Martinus Nijhoff.

HUSSERL, Edmund (2000). Aktive Synthesen: Aus der Vorlesung 'Transzendentale Logik' 1920/21. Ergänzungsband zu 'Analysen zur passiven Synthesis'. Husserliana XXXI. The Hague: Kluwer Academic Publishers.

— (1977). Ideen zu einer reinen Phänomenologie und phänomenologischen Philosophie. Erstes Buch: Allgemeine Einführung in die reine Phänomenologie. Husserliana III/1. The Hague: Martinus Nijhoff.

- (1966). Analysen zur passiven Synthesis. Aus Vorlesungs- und Forschungsmanuskripten, 1918-1926. Husserliana XI. The Hague: Martinus Nijhoff.

- (1952). Ideen zur einer reinen Phänomenologie und phänomenologischen Philosophie. Zweites Buch: Phänomenologische Untersuchungen zur Konstitution. Husserliana IV. The Hague: Martinus Nijhoff.

- (1939). Erfahrung und Urteil. Untersuchungen zur Genealogie der Logik. Prag: Academia.

MiCALI, Stefano (2008). Überschüsse der Erfahrung. Grenzdimensionen des Ich nach Husserl. Dordrecht: Springer. 
STEINBOCK, Anthony (1995). Home and Beyond: Generative Phenomenology after Husserl. Evanston: Northwestern University Press.

Pedro M. S. Alves is Associate Professor (tenured) at the Faculty of Arts of the University of Lisbon. He also is senior-researcher at the Center of Philosophy of the University of Lisbon (CFUL). His main areas of interest are husserlian phenomenology, transcendental philosophy, philosophy of nature, and philosophy of law. He publishes regularly on these fields. His main monographic studies are: Studia Kantiana. Interpretação e Crítica (2009); Intersubjectividade e comunicação: Uma abordagem fenomenológica (2009); Subjectividade e Tempo na Fenomenologia de Husserl (2003); and Fenomenología del tiempo y de la percepción (2010). 